\title{
Heterotropic pregnancy following induction of ovulation with clomiphene
}

\author{
Sangeeta Raman Jogi*, Kavita Babbar
}

Department of Obstetrics and Gynecology, Chhattisgarh Institute of Medical Sciences,

Bilaspur-495001, CG, India

Received: 19 June 2015

Revised: 26 June 2015

Accepted: 10 July 2015

\section{*Correspondence:}

Dr. Sangeeta Raman Jogi,

E-mail: raman.jogi@yahoo.com

Copyright: (c) the author(s), publisher and licensee Medip Academy. This is an open-access article distributed under the terms of the Creative Commons Attribution Non-Commercial License, which permits unrestricted non-commercial use, distribution, and reproduction in any medium, provided the original work is properly cited.

\section{ABSTRACT}

Hetrotopic pregnancy is a rare entity with a difficult preoperative diagnosis and potentially dangerous outcome.

A case of 36 years old $\mathrm{G}_{3} \mathrm{P}_{2}$ had received Clomiphen Citrate for three cycles for ovulation induction presented with amenorrhea for two months with severe pain in abdomen and bleeding.

She was diagnosed as a case of right ectopic with 8 weeks of intrauterine pregnancy.

Keywords: Hetrotopic pregnancy, Clomiphen citrate, Ovulation induction

\section{INTRODUCTION}

The coexistence of intrauterine pregnancy and ectopic pregnancy is called Heterotropic Pregnancy. It is a rare entity. The incidence of heterotropic pregnancy has been calculated as 1 in 30,000 spontaneous pregnancies. ${ }^{1}$ However, it occurs more frequently in women undergoing ovulation induction. Occurrence of heterotropic pregnancies among patients who have undergone one of the assisted reproductive technologies is much higher, closer to 1 in 100 pregnancies. $^{2}$

\section{CASE REPORT}

A 36yrs old women,G3P2-2FTND with two female children, alive and healthy was reported On $14^{\text {th }}$ July 2014 in the emergency hours with complains of amenorrhea two months, severe pain in abdomen and bleeding per vagina since few hours. Her LMP was on 7th May 2014.She conceived after three cycles of ovulation induction with clomiphen at primary care setting.

On examination - She was markedly pale with a heart rate of $110 / \mathrm{min}$, and blood pressure of $90 / 50 \mathrm{~mm}$ of $\mathrm{Hg}$. The abdomen was distended, tenderness was present all over the abdomen with guarding and rigidity. Bowel sounds were absent.

On virginal examination uterus was soft 8 to 10 weeks size, mild bleeding present, external os tip of finger and internal os closed. Cervical movements are tender, both fornix were very tender. Urgent ultra sounds scan of the abdomen showed moderate free fluid in the abdomen. Uterus is bulky with a well-defined gestational sac in the uterus with good vascularity seen around, with secondary yolk and embryo.

Ges sac $-2.69 \mathrm{~cm}=8$ weeks0 days, CRL $-0.65 \mathrm{~cm}=6$ weeks3days, EDD = 28 Feb 2015 .

Cx normal with internal os is closed. An ill-defined mixed ecogenecity lesion of size $5.5 \times 5.0 \mathrm{~cm}$ seen in right adenexa involving right ovary and fallopian tube.

A peritoneal tap showed a bloody aspirate. Urinary pregnancy test was positive. Her $\mathrm{Hb}$ was $6.5 \mathrm{gm} \%$, blood gorup B+ ve, and Leukocyte count 12,600/mm3, HIV-ve, HBs Ag-ve. 
She was immediately posted for emergency laprotomy after resuscitation and arrangement of two units of blood. On opening the abdominal cavity hemoperitoneum was found of approximately $1000 \mathrm{ml}$ with clots. Right tube was adherent with ovary and embedded in clots. After removing clots it was found that ampulary region of right tube is engorged and distorted, active bleeding and clots were present at fimbria. Right salpingectomy was performed. Uterus was soft and 8 to 10 weeks size and left tube and ovaries were normal. After peritoneal cleaning abdomen was closed. Right tube and sac was sent for histopathology that confirmed the diagnosis of right tubal pregnancy. Two units of fresh blood were transfused. She was kept under I/V Isoxsuprine Hydrochloride drip, hydroxy progesterone caporate 500 mg Intramuscular weekly and BetaHCG 5000 IU intramuscularly for four weeks from fourth day onwards she was shifted on oral Isoxsuprine Hydrochloride tablets and micronized progesterone and folic acid tablet. On 8th postoperative day sutures were removed and she was discharged on the same day.

After one month she came back and a repeat Doppler study confirmed the intact and healthy intra uterine gestation. She was follow up with serial Ultra Sound and she delivered a full term healthy male baby by LSCS on 21 st Feb 2015.

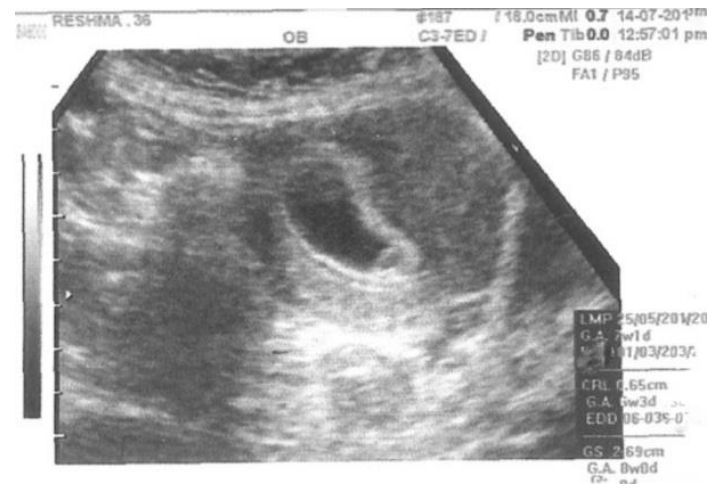

Figure 1: Uterus with well defined gestational sac with secondary yolk and embryo.

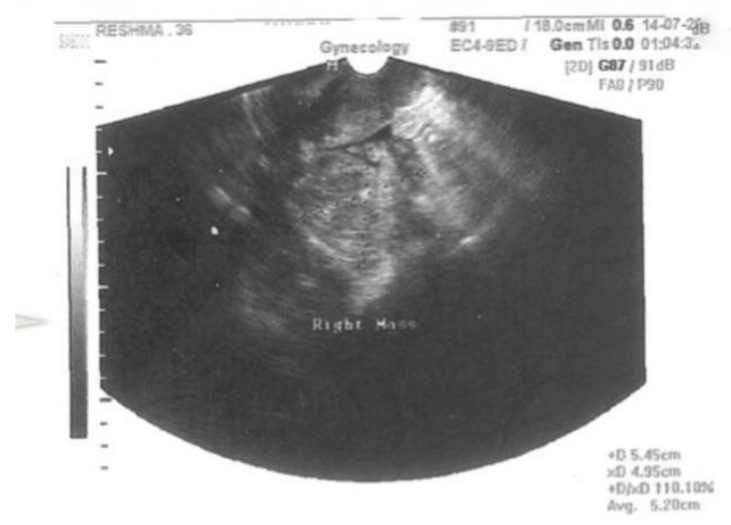

COMPLEX RIGHT ADNEXAL MASS

Figure 2: Complex right adnexal mass

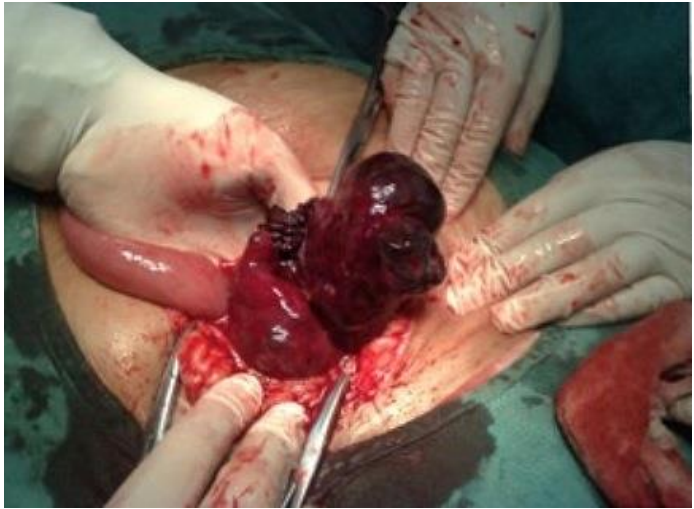

Figure 3: Fallopian tube embedded in Clots.

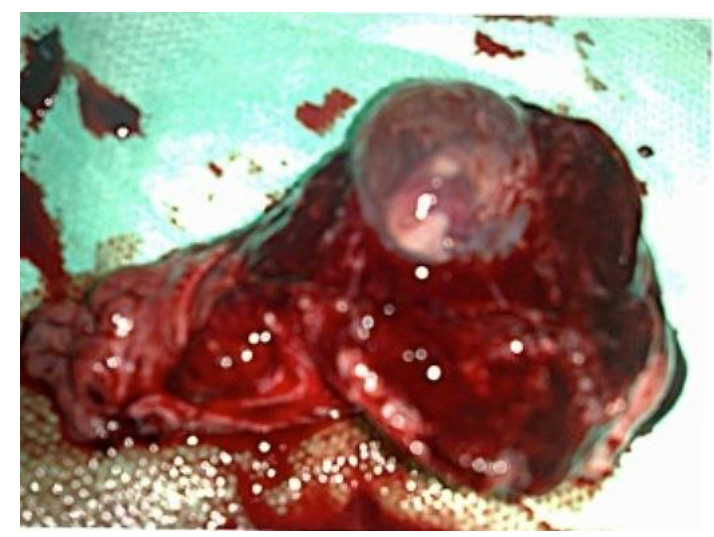

Figure 4: Uterus with Right tube engorged and lacerated with clot

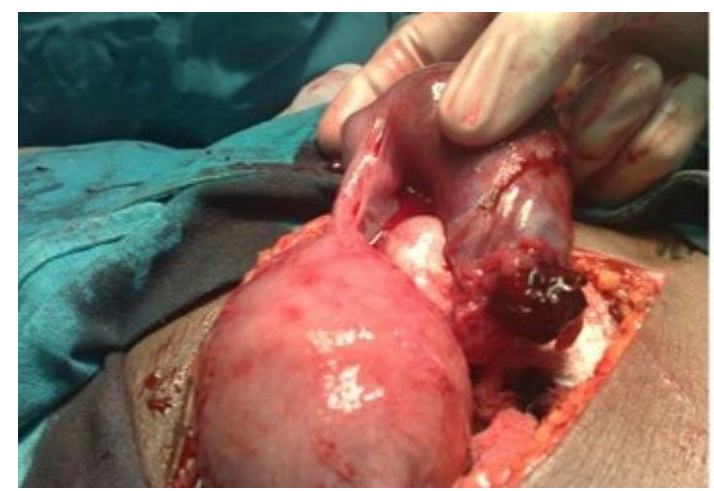

Figure 5: Cut section of ampulary part of fallopian tube with Gestational sac and Clot

\section{DISCUSSION}

Heterotrophic pregnancy a rare condition first described by Duverney in 1708 , it represents a form of dizygotic twinning with separate sides of implantation of blastocyst. ${ }^{1}$ The incidence is increased with use of ovarian stimulation with IVF it is about $1 / 35-1 / 100$ clinical pregenancies. ${ }^{3}$

Selvaraj $\mathrm{K}$ et al. ${ }^{4}$ reported $0.49 \%$ risk of Heterotropic pregnancy after IVF and with IUI it is $0.16 \%$ in their series. The authors found that the risk HTP appeared to increase with the number of embryo transfer. 
The first case of HTP following clomiphen-induced ovulation was reported in 1971. Clomiphen by hyperstumilating ovaries and probably by altering the myoelectrical activity responsible for propulsive action of fallopian tubes. ${ }^{5,6}$

Yelamanchi S et al. ${ }^{6}$ reported incidence of HTP in there study was 1.3/1000 deliveries. Early diagnosis of HTP is important for the intrauterine fetus and the mother. The options of management like Medical treatment (potassium chloride, methotrexate and prostaglandins) are available but surgical intervention is better approach than medical management for intrauterine pregnancy in Hetrotropic pregnancies. ${ }^{6,7}$

Combination of pelvic pain, adnexal mass, peritoneal irritation and enlarged uterus are the major clinical features associated with combined pregnancy. Diagnosis of this rare condition will be difficult and careful ultra sound examination is mandatory. Beta HCG levels are unreliable and misleading for diagnosis. Trans vaginal ultra sound is more reliable..$^{3,7,8}$ A diagnostic laparoscope examination should be performed whenever the diagnosis remains unclear. ${ }^{9-12}$ HTP is no longer a medical curiosity a high index of suspicion, prompt diagnosis, rapid fluid and blood infusion and early intervention are required to salvage the intrauterine pregnancy and to prevent maternal morbidity and mortality. There is a need to consider it in the differential diagnosis of abdominal pain in pregnancy especially after ovulation induction. CC that is used quite frequently by most of the practitioners is felt safe by them but it should be used with caution.

Funding: No funding sources

Conflict of interest: None declared

Ethical approval: Not required

\section{REFERENCES}

1. Cunningham FG, MacDonald PC, Gant NF. Williams's obstetrics. In: Cunningham FG, MacDonald PC, Gant
NF, eds. A Book. 23rd ed. New York: McGraw-Hill; 2010;10:238-256.

2. David K. Gardener, Ariel. Weissmam. The text book of Assisted Reproductive Technologies. CRC Press UK; 3rd ed 2008;08:791.

3. Mittal P,Acharya V,Nupur Hooja,Kalyan Sahay. Heterotropic ectopic pregnancy. J obstet Gynecology Ind. 2004;54:505.

4. Selvaraj Kamla, Selvaraj Priya. Heterotopic pregnancy following assisted conception. J obstet Gynecology Ind. 2006;56:427-30.

5. Kumari I, Goyel Punam. Heterotropic pregnancy following induction of ovulation with clomiphen. J obstet Gynecol Ind. 2004;54:87-8.

6. Puri, Suman Goel, Anupama. Heterotropic pregnancy following induction of ovulation with clomiphen and viable intrauterine fetus. $\mathbf{J}$ obstet Gynecol Ind. 2007;57:556-7.

7. Yelamanchi SD, Vendru KS. Heterotropic pregnancy. J obstet Gynecol Ind. 2003;53:385-8.

8. Janki Radhkrishnan, P Panigrahi.Coexisting extra and intrauterine pregnancy $\mathbf{J}$ obstet Gynecol Ind. 2003;53:392.

9. Seshi Iyar, Mamta rath Dutta, Renu Sinha, Manus Kaviraj. Heterotropic pregnancy two case report. J obstet Gynecol Ind. 2006;53:192.

10. Adhikari S, S Mumtaz, Deshgupta M. Heterotropic pregnancy continuing after tubal abortion. J obstet Gynecol Ind. 2007;54:502.

11. Mohan S Kamath et all; A rare cae report-Ovarian Hetrotopic Pregnancy after in vitro fertilisation. Fertility and sterility. 2010;94(5):1910.

12. Francesca Basil et all; Sponteneous Hetrotopic pregnancy, stimultaneous ovarian and intrauterine: a case report, Case reports in Obstetrics and Gynaecology. 2012;Artical ID:509694:1-4.

Cite this article as: Jogi SR, Babbar K. Heterotropic pregnancy following induction of ovulation with clomiphene. Int J Reprod Contracept Obstet Gynecol 2015;4:1241-3. 